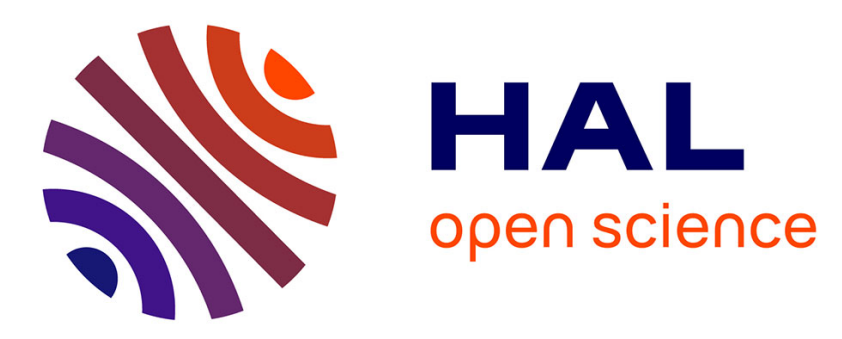

\title{
Fast Neutron Spectroscopy with a Nitrogen-Based Gaseous Detector
}

I. Katsioulas, I. Giomataris, P. Knights, T. Neep, K. Nikolopoulos, T. Papaevangelou, R. Ward

\section{- To cite this version:}

I. Katsioulas, I. Giomataris, P. Knights, T. Neep, K. Nikolopoulos, et al.. Fast Neutron Spectroscopy with a Nitrogen-Based Gaseous Detector. 2019 IEEE Nuclear Science Symposium (NSS) and Medical Imaging Conference (MIC), Oct 2019, Manchester, United Kingdom. pp.1-3, 10.1109/NSS/MIC42101.2019.9060052 . hal-02614346

\section{HAL Id: hal-02614346 https://hal.science/hal-02614346}

Submitted on 8 Jul 2020

HAL is a multi-disciplinary open access archive for the deposit and dissemination of scientific research documents, whether they are published or not. The documents may come from teaching and research institutions in France or abroad, or from public or private research centers.
L'archive ouverte pluridisciplinaire HAL, est destinée au dépôt et à la diffusion de documents scientifiques de niveau recherche, publiés ou non, émanant des établissements d'enseignement et de recherche français ou étrangers, des laboratoires publics ou privés. 


\title{
Fast Neutron Spectroscopy with a Nitrogen-Based Gaseous Detector
}

\author{
I. Katsioulas, I. Giomataris, P. Knights, T. Neep, K. Nikolopoulos, T.Papaevangelou, R. Ward
}

\begin{abstract}
A simple, efficient and safe to use but also affordable fast neutron spectroscopic system is the Holy Grail in many scientific and industrial communities. ${ }^{3} \mathrm{He}$ based detectors provide a solution that fulfils most of the requirements but its high demand combined with its scarcity has created a worldwide shortage and efforts are focused on finding an alternative solution. Several detectors are proposed for this task, such as $\mathbf{B F}_{3}$ proportional counters, plastic scintillators, and recoil detectors, all with disadvantages that make their adoption far from ideal. We propose a system based on a spherical proportional counter filled with nitrogen-based gas mixtures to exploit the ${ }^{14} N(n, \alpha) B^{11}$ and ${ }^{14} \mathrm{~N}(\mathbf{n}, \mathbf{p}) \mathrm{C}^{14}$ reactions for the detection of fast neutrons. ${ }^{3} \mathrm{He}$ and $\mathbf{N}_{2}$ have comparable Q-values and absorption cross-sections for fast neutron capture, offering similar detection capabilities. In the future, such a detector could be utilised in industrial applications such as reactor monitoring, medical physics, accelerator facilities, homeland security, fuel searches and serve as a tool in scientific research.
\end{abstract}

\section{INTRODUCTION}

A simple, efficient, yet affordable fast neutron spectroscopy system is sought after by many scientific and industrial communities but with little success. Several attempts were made for an efficient spectroscopy system based on various detector technologies [1]. However, neutron measurements remain cumbersome, as demonstrated by the sparsity of detailed neutron spectra in many laboratories and industrial sites.

The most popular method is that of ${ }^{3} \mathrm{He}$ based detectors, as it has high efficiency for thermal neutrons through the ${ }^{3} \mathrm{He}(\mathrm{n}, \mathrm{p}) \mathrm{He}^{3}\left(\sigma_{t h}=5330 \mathrm{~b}\right)$ reaction and very low efficiency in $\gamma$-ray detection. ${ }^{3} \mathrm{He}$ is not flammable and non-toxic, while detectors using it are radiation hard and have a long lifetime. For fast neutrons detection using ${ }^{3} \mathrm{He}$, usually cylindrical proportional counters are employed operated in pulsed mode for $\gamma$-ray discrimination [2] in high pressure or ${ }^{3} \mathrm{He}$ gaseous scintillators in pressure close to 150 bar.

Because of its popularity, ${ }^{3} \mathrm{He}$ demand is disproportionate to production, dramatically increasing its price. Consequently, ${ }^{3} \mathrm{He}$ based detectors require expensive retrieval systems, leading governments and industries to search for alternatives. Existing alternatives [6], [7] have disadvantages prohibiting

This project has received funding from the European Union's Horizon 2020 research and innovation programme under grant agreement no 841261 (DarkSphere)

I. Katsioulas, T. Neep, K. Nikolopoulos, and R.Ward are with the School of Physics and Astronomy, University of Birmingham, B15 2TT, United Kingdom

I. Giomataris and T.Papaevangelou are with IRFU, CEA, Universite ParisSaclay, Gif-sur-Yvette, F-91191, France

P. Knights is with the School of Physics and Astronomy, University of Birmingham, B15 2TT, United Kingdom and with IRFU, CEA, Universite Paris-Saclay, Gif-sur-Yvette, F-91191, France them replacing ${ }^{3} \mathrm{He}$ detectors: i) $\mathrm{BF}_{3}$ proportional counters$\mathrm{BF}_{3}$ is a toxic and corrosive gas; ii) ${ }^{10} \mathrm{~B}$ lined tubes-Poor efficiency, and a high cost; iii) Bulk scintillators- Complicated response functions and an insufficient $\gamma / \mathrm{n}$ separation along with limited radiation hardness; iv) ${ }^{6} \mathrm{Li}$ coated argon based detectors- ${ }^{6} \mathrm{Li}(\mathrm{n}, \alpha) \mathrm{H}^{3}$ reaction has a high $\mathrm{Q}$-value $(2.79 \mathrm{MeV})$ affecting resolution.

\section{The FAST NEUTRON SPECTROSCOPY SYSTEM}

A nitrogen-based neutron detection system aspires to provide an alternative to ${ }^{3} \mathrm{He}$ based detectors for neutron spectroscopy. The detection relies on the ${ }^{14} \mathrm{~N}(\mathrm{n}, \alpha) \mathrm{B}^{11}$ and ${ }^{14} \mathrm{~N}(\mathrm{n}, \mathrm{p}) \mathrm{C}^{14}$ reactions, with the neutron energy determined through the measurement of the reaction charged products with a gaseous proportional counter. Early explorations of this idea are discussed in Ref. [9]. The cross-section of the ${ }^{3} \mathrm{He}(\mathrm{n}, \mathrm{p}) \mathrm{He}^{3}$

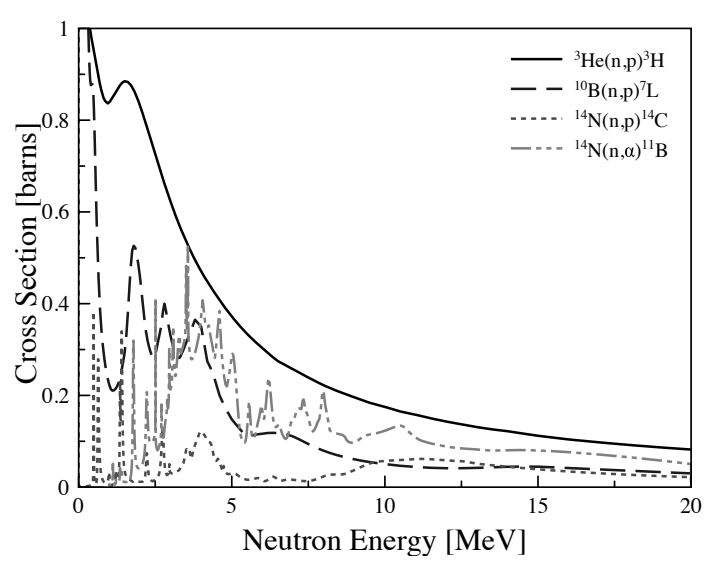

Fig. 1. Comparison of the ${ }^{3} \mathrm{He}(\mathrm{n}, \mathrm{p}) \mathrm{He}^{3},{ }^{10} \mathrm{~B}(\mathrm{n}, \alpha) \mathrm{Li}^{7},{ }^{14} \mathrm{~N}(\mathrm{n}, \mathrm{p}) \mathrm{C}^{14}$ and ${ }^{14} \mathrm{~N}(\mathrm{n}, \alpha) \mathrm{B}^{11}$ neutron reaction cross sections for energy up to $20 \mathrm{MeV}$ [9].

reaction although higher is comparable to the ${ }^{14} \mathrm{~N}(\mathrm{n}, \alpha) \mathrm{B}^{11}$ and ${ }^{14} \mathrm{~N}(\mathrm{n}, \mathrm{p}) \mathrm{C}^{14}$ cross sections for fast neutrons as displayed in Fig. 1 and can be compensated by the higher number of atoms in $\mathrm{N}_{2}$ and the much-reduced wall-effect. Also, although nitrogen has a much lower thermal neutron absorption crosssection (1.83 b), due to the large number of atoms in a sensitive volume it could nonetheless prove to be efficient for thermal neutron counting.

Traditionally, the operation of nitrogen-filled gaseous detectors in atmospheric pressure or above has been challenging due to the high voltage required to reach proportional mode operation. Equally daunting has been the task of ensuring containment of the resulting $\mathrm{MeV}$-range protons or alpha particles 


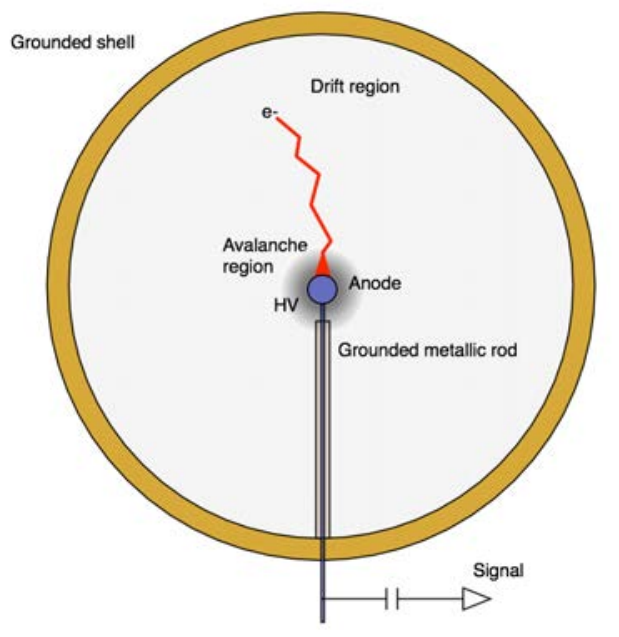

Fig. 2. The spherical proportional counter design and its principle of operation.

within a detector's sensitive volume. That is the reason why ${ }^{3} \mathrm{He}$-filled cylindrical proportional counters are used mainly as flux monitors and rarely for spectroscopy. These challenges are addressed by the use of a Spherical Proportional Counter (SPC).

\section{The Spherical Proportional Counter}

The SPC, shown in Fig.2, consists of a grounded spherical shell (cathode) and a small sphere (anode) placed at the centre of the shell, supported by a grounded metallic rod, to which high voltage is applied and from which the signal is read-out. The $1 / \mathrm{r}^{2}$ dependence, where $\mathrm{r}$ is the radius from the centre, of the electric field results in large charge multiplication factors with anode diameters of $O(\mathrm{~mm})$, and thus is more robust and reliable detector construction compared to cylindrical counters. Details on the SPC and its advantages compared to other detector geometries can be found in [3], [4], [11]. The pulseshape dependence on the nature of the interaction (interaction radius, track length, orientation, clustering) provides handles to discriminate events using a small number of parameters (pulse height, rise time or width) [5]. The background discrimination capability greatly improves the performance for neutron detection through rejection of $\gamma$-induced background and partial energy depositions. These features and the inherent low $\gamma$-ray efficiency of gaseous detectors make such a system ideal for mixed $\gamma / \mathrm{n}$ environments.

\section{Operations at the University of Birmingham}

The detector used in the University of Birmingham (UoB) is a 30-cm-diameter stainless steel SPC. The detector is operated in sealed mode after being filled with pure nitrogen which has been filtered to reduce contaminants $\left(\mathrm{O}_{2}, \mathrm{H}_{2} \mathrm{O}\right)$ to parts per trillion level. The detector is equipped with resistive sensors developed for high-gain, high-pressure operation [8] and can withstand high voltages applied over $6 \mathrm{kV}$. The experimental setup is displayed in Fig.3. The detector calibration, shown in

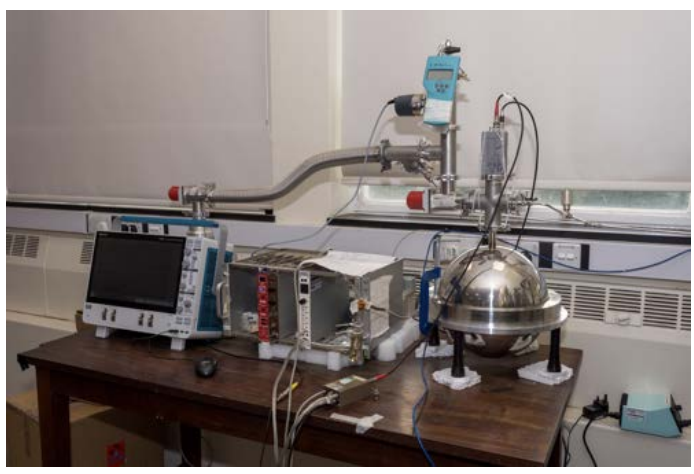

Fig. 3. The experimental setup in the University of Birmingham (Photo credit: R. Owen).

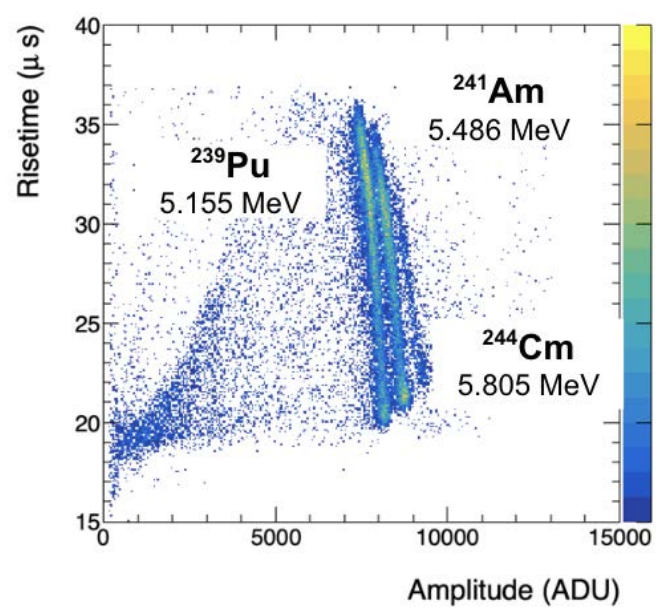

Fig. 4. Rise time versus amplitude distribution displaying the detector calibration using alphas sources. The detector was filled with $300 \mathrm{mbar}$ of nitrogen.

Fig.4, is done using radiation sources such as ${ }^{239} \mathrm{Pu},{ }^{241} \mathrm{Am}$, ${ }^{244} \mathrm{Cm}$ that emit alpha particles with energy of a few $\mathrm{MeV}$ and characterised using fast neutrons sources such as $\mathrm{Cf}^{252}$ and ${ }^{241} \mathrm{Am}-{ }^{9} \mathrm{Be}$. Furthermore, the detector capability to discriminate $\gamma$-rays from neutron-induced events using $\gamma$-sources such as ${ }^{137} \mathrm{Cs}$ is studied, before the system can be moved to mixed radiation environments.

The response of the detector is simulated using a framework developed at UoB based on GEANT4 and Garfield++ for high energy physics applications, more details can be found in [10]. As an example, shown Fig.5 is the rise time versus amplitude distribution of simulated pulses of events induced by $4 \mathrm{MeV}$ neutrons interacting with the nitrogen nuclei in a $30-\mathrm{cm}-$ diameter detector. The simulated response is being compared with measurements for validation. Finally, a series of measurements are under consideration in the UoB's MC40 cyclotron and in underground laboratories, attempting to emulate hadron therapy environments and to improve the neutron background estimation of rare-event experiments respectively. 


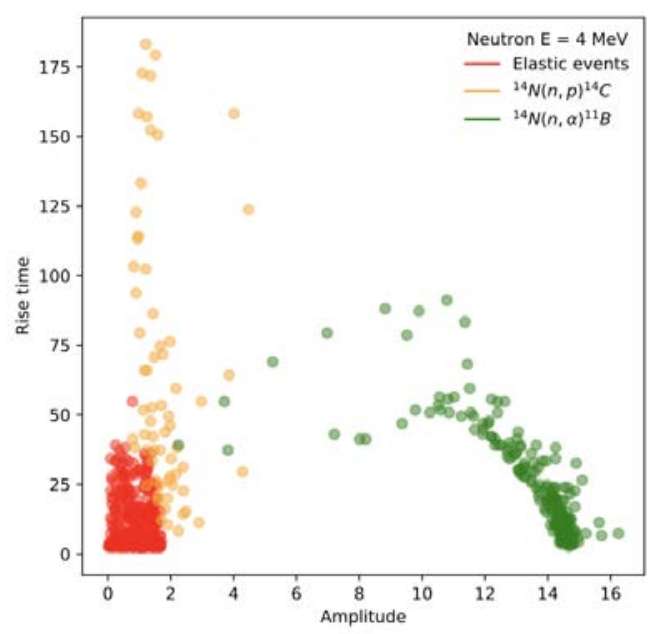

Fig. 5. Rise time versus amplitude distribution of simulated events from $4 \mathrm{MeV}$ neutrons interacting with the nitrogen nuclei in a 30-cm-diameter detector. Green points are events coming from the ${ }^{14} \mathrm{~N}(\mathrm{n}, \alpha) \mathrm{B}^{11}$ reaction, yellow points are events from the ${ }^{14} \mathrm{~N}(\mathrm{n}, \mathrm{p}) \mathrm{C}^{14}$ reaction, and red points are elastic scattering events.

\section{Applications}

This neutron detection system is aimed to be applied initially to measurements of neutron backgrounds in underground laboratories (where rare event searches take place), reactor driven experiments and to measurements of fast neutrons in hadron therapy environments. Developments that could improve the sensitivity in a large number of experiments and create a safer environment for patients and medical staff.

Nevertheless, the main goal is the development of a system that could to be used in industrial applications: reactor monitoring, medical physics, accelerator facilities, homeland security, fuel searches, space science and other.

\section{Conclusions}

A nitrogen-filled SPC presents a simple, robust, and reliable fast neutron spectroscopy system. The use of a large volume gaseous detector, such as the SPC, filled with a nitrogenbased mixture, provides an ideal alternative to a ${ }^{3} \mathrm{He}$-based fast neutron spectrometer. A gaseous nitrogen mixture can provide good efficiency for the detection of fast neutrons, without moderation, and limited influence from $\gamma$-rays. The nitrogen-based detector exhibits the desired features of ${ }^{3} \mathrm{He}$ counters and can pioneer a line of detectors with alternatives designs, more compact or larger to cover different needs. The nitrogen-based spectroscopic system is being developed and tested at the University of Birmingham. The detector response is studied using simulations based on GEANT4 and Garfield++ validated through measurements with alpha and fast neutron sources. Such a fast neutron spectroscopy system will facilitate neutron measurements in laboratories, sensitive environments and industrial sites.

\section{REFERENCES}

[1] Brooks, F., Klein, H. (2002). Neutron spectrometry-historical review and present status. Nuclear Instruments and Methods in Physics Research Section A: Accelerators, Spectrometers, Detectors and Associated Equipment, 476(1-2), 1-11. https://doi.org/10.1016/S0168-9002(01)01378-X

[2] Knoll, G. F. (2010). Radiation detection and measurement.

[3] Katsioulas, I. (2018). NEWS-G, Light dark matter search with a Spherical Proportional Counter, First results and Future prospects. Retrieved from http://arxiv.org/abs/1809.02485

[4] Arnaud, Q. et al (2018). Spherical Proportional Counter: A review of recent developments. Journal of Physics: Conference Series, 1029(1), 012006. https://doi.org/10.1088/1742-6596/1029/1/012006

[5] Savvidis, I. et al (2018). Low energy recoil detection with a spherical proportional counter. Nuclear Instruments and Methods in Physics Research Section A: Accelerators, Spectrometers, Detectors and Associated Equipment, 877, 220-226. https://doi.org/10.1016/J.NIMA.2017.09.014

[6] Kouzes, R. et al (2010). Neutron detection alternatives to $3 \mathrm{He}$ for national security applications. Nuclear Instruments and Methods in Physics Research Section A: Accelerators, Spectrometers, Detectors and Associated Equipment, 623(3), 1035-1045. https://doi.org/10.1016/J.NIMA.2010.08.021

[7] Simpson,A. P. INMM 52nd Annual Meeting (2011)

[8] Katsioulas, et al. (2018). A sparkless resistive glass correction electrode for the spherical proportional counter. Journal of Instrumentation, 13(11), P11006-P11006. https://doi.org/10.1088/1748-0221/13/11/P11006

[9] Bougamont, et al (2017). Neutron spectroscopy with the Spherical Proportional Counter based on nitrogen gas. Nuclear Instruments and Methods in Physics Research, Section A: Accelerators, Spectrometers, Detectors and Associated Equipment, 847, 10-14. https://doi.org/10.1016/j.nima.2016.11.007

[10] R. Ward, et al, (2019). Development of a Simulation Framework for Spherical Proportional Counters, IEEE N-32-2 Experimental Computing

[11] P. Knights, et al, (2019). Recent developments in the read-out electrodes for Spherical Proportional Counters, IEEE N-32-2 Gaseous Detectors I 